\title{
Surface topography and mechanical properties of flax fibres modified glass ionomer restorative materials
}

\author{
Ensanya Ali Abou Neel ${ }^{1,2,3}$, Wojciech Chrzanowski ${ }^{4}$ \\ 1. Division of Biomaterials, Operative Dentistry Department, King Abdulaziz University, Jeddah, Saudi Arabia. 2. Bio- \\ materials Department, Faculty of Dentistry, Tanta University, Tanta, Egypt. 3. Division of Biomaterials and Tissue \\ Engineering Division, UCL Eastman Dental Institute, London, UK. 4. The University of Sydney, The Faculty of Pharmacy, \\ NSW, Sydney, Australia
}

Correspondence: Associate Prof. Ensanya Ali Abou Neel. Address: Division of Biomaterials, Operative Dentistry Department, Faculty of Dentistry, King Abdulaziz University, Jeddah, Saudi Arabia.

Email: eabouneel@kau.edu.sa; e.abouneel@ucl.ac.uk

Received: July 4, 2015

Accepted: August 6, 2015

Online Published: August 17, 2015

DOI : $10.5430 /$ jbei.v1n1p82

URL: http://dx.doi.org/10.5430/jbei.v1n1p82

\section{Abstract}

Objectives: Regardless of the excellent adhesive and biological properties of glass ionomer cements (GICs), their poor mechanical properties and abrasion resistance limit their application to non-load bearing areas. This study aimed to investigate the effect of flax fibres incorporation on surface and mechanical properties of GIC filling materials.

Methods: Short chopped flax fibres were randomly incorporated into GIC at 0, 0.5, 1, 2.5, 5 and $25 \mathrm{wt} \%$. Surface hardness, distribution of different phases, stiffness map, phase separation and uniformity of the material were investigated.

Results: Addition of flax fibres produced no significant change in Vicker hardness number of GIC. Qualitative imaging using atomic force microscopy showed the presence of a single phase in GIC, while biphasic structure was observed for flax fibres modified GICs (FFMGICs). For all tested formulations, the flax fibres, however, were uniformly distributed and well integrated within the GIC matrix without any visible interfacial separation. Incorporation of flax fibres was associated with a significant increase in surface roughness and stiffness. The roughness values obtained for all tested formulations, however, are far below the threshold values for bacterial adhesion and plaque accumulation.

Conclusions: Flax fibres modified GICs could be potentially used in high stress bearing areas.

\section{Key words}

Glass ionomer, Hardness, Surface roughness, Atomic force microscopy, Amplitude modulated force spectroscopy

\section{Introduction}

Due to its adhesion to tooth structures, biocompatibility and anticariogenic action, the conventional glass ionomer cement (GIC) has been widely used as a filling material. One of its common limitations, however, is its low mechanical properties and its susceptibility to abrasion and scratching by hard tooth brushing.

Several modifications have been carried out to improve the mechanical strength and degradation resistance of GIC. Addition of silver-amalgam alloy was effective in enhancing the strength but impaired the aesthetic quality of GIC. A 
sol-gel niobium modified GIC showed higher mechanical properties and reduced degradation than the conventional GIC $^{[1-3]}$, but its biocompatibility with the dentin-pulp complex, however, has not been tested ${ }^{[4]}$.

To eliminate any concern about the biocompatibility issue, natural products found great interest for biomedical applications. Flax fibres, as an example of biologically produced products, are commonly used for both industrial ${ }^{[5,6]}$ and biomedical field ${ }^{[7,8]}$. Due to their antibacterial action, flax fibres were used as wound dressing ${ }^{[7]}$. For dental applications, flax fibres were effective in improving the compressive strength while reducing the degradation of zinc oxide eugenol cement ${ }^{[9]}$.

Surface topography (e.g., roughness \& free energy) of intraoral hard surfaces and restorations has a great influence on the initial adhesion and retention of microorganisms, Streptococcus Mutans in particular ${ }^{[10,11]}$. Accumulation of dental plaque and consequent risk of caries and periondontal inflammation can easily occur with rough surfaces ${ }^{[12-15]}$. Proper finishing and polishing is therefore an essential clinical practice for aesthetic and durable restorations ${ }^{[16]}$.

Surface roughness can be measured qualitatively by scanning electron microscopy ${ }^{[17,18]}$ or quantitatively by profilemetry ${ }^{[19]}$ and light sectioning microscopy ${ }^{[20]}$. Recently, the atomic force microscopy (AFM) showed high capability to reveal more detailed information of surface topography ${ }^{[21]}$ of resin composites after various treatments e.g., mechanical tooth brushing ${ }^{[22]}$, different polishing protocols ${ }^{[23]}$ or in-office bleaching ${ }^{[24]}$. AFM produces a 3-D imaging of the surface at nanoscale level with no need for any sample preparation. It can also produce a high resolution quantitative map of the mechanical properties ${ }^{[25]}$ and stiffness of the material ${ }^{[26]}$.

In this study, the conventional GIC restorative material was modified with randomly distributed short chopped flax fibres that were incorporated into the GIC powder at 0, 0.5, 1, 2.5, 5 and $25 \mathrm{wt} \%$. These fibres were incorporated in an attempt to improve the mechanical properties while maintaining the good biocompatibility of GIC. The aim of this study was therefore to test the hardness, as a surface mechanical property, surface roughness and mechanical properties at nano-scale level of flax fibres modified GICs. The null hypothesis was that "addition of flax fibres has no effect on surface properties (roughness \& hardness) and modulus of glass ionomer filling materials”.

\section{Materials and methods}

\subsection{Samples preparation}

Short flax fibres (675 $\pm 255 \mu \mathrm{m}$ length and $10 \mu \mathrm{m}$ diameters) and glass ionomer filling materials (Ketac ${ }^{\mathrm{TM}}$ Fil Plus, $3 \mathrm{M}$ ESPE, Germany, shade $3.5 \mathrm{~A}$ ) were used for this study. Fibres were included at 0, 0.5, 1, 2.5, 5 and $25 \mathrm{wt} \%$ and samples were coded as GIC, 0.5 FFMGIC, 1 FFMGIC, 2.5 FFMGIC, 5 FFMGIC and 25 FFMGIC. The powder/liquid (P/L) ratio was fixed at 3:1. The required amount of powder and liquid was weighted using an electronic balance (Shimadzu Corporation, Tokyo, Japan). For proper distribution of flax fibres, they were properly mixed with the powder before the addition of liquid. The cement was mixed according to the manufacturer's instruction. Disc shaped specimens of $8 \mathrm{~mm}$ diameter and $3 \mathrm{~mm}$ thickness were prepared from each composition using a transparent rubber mould. The rubber mould was set on the top of a glass slab and a celluloid strip. The material was inserted into the mould with a slight excess of material used to fill the mould. Another celluloid strip was then placed on the top of the filled mould; the material surface was pressed flat with another glass slab. The glass slab was held firmly in place for few minutes to avoid air bubbles incorporation and to obtain a flat and smooth surface. After 15 minutes, the celluloid strips and glass slabs were removed and then the excess material. Each disc was then smoothed from both sides with silicon carbide papers of grit size \#240 then followed by \#600; the surfaces of each disc, however, were left untouched. The samples were then kept in a plastic bag until use. 


\subsection{Microhardness}

The hardness of disc shaped specimen ( $\mathrm{n}=5$ for each composition) was determined using the HMV- microhardness tester (Shimadzu Corporation, Tokyo, Japan) with a diamond Vickers indenter. Five indentations were performed along the cross sectional area of each specimen with a $1.96 \mathrm{~N}$ load and $5 \mathrm{~s}$ dwell time. The diagonal length of the indentation was measured under $\times 40$ magnification and the Vickers microhardness number (VHN) for each specimen was taken as the average of these five readings. One way analysis of variance (ANOVA) was used to test the significance between the obtained results at 0.05 level.

\subsection{Surface topography and mechanical properties}

Surface topography and mechanical properties were investigated using Molecular Force Probe (MFP-3D-Bio, Research Asylum). Samples (GIC, 1 FFMGIC, 5 FFMGIC and 25 FFMGIC) were mounted on the sample holder and placed on the microscope stage. Three samples were used for each formulation. Samples were scanned using amplitude modulated force microscopy mode (AMFM), which enable continues mapping of mechanical properties. To calculate Young's modulus, control sample (microtomed polycarbonate) was scanned to establish reference scanning parameters. Samples were scanned using silicon tip with nominal spring constant $40 \mathrm{~N} / \mathrm{m}$; for each tip spring constant was established using thermal method and the sensitivity was calculated from single force measurements-deflection curve obtained by the indentation to freshly cleaved mica. Samples were scanned at frequency $0.5 \mathrm{~Hz}$ and scan size was $1 \times 1,5 \times 5$, and $10 \times 10 \mu \mathrm{m}^{2}$.Collected data allowed generating topographical images, distribution of different phases in the material, maps of stiffness and energy dissipation which corresponded with phase separation and uniformity of the material.

\section{Results}

\subsection{Microhardness}

Vicker hardness of $\mathrm{Ketac}^{\mathrm{TM}}$ Fil Plus is $95 \pm 13$; addition of $0.5 \mathrm{wt} \%$ flax fibres reduced the hardness number to $83 \pm 13$. Addition of $1 \mathrm{wt} \%$ flax fibres increased the hardness number to $114 \pm 17$. Further addition of flax fibres (2.5, 5 and $25 \mathrm{wt} \%)$ reduced the hardness to $99 \pm 12,90 \pm 11$ and $94 \pm 23$ respectively. The produced change in hardness number with the addition of flax fibres, however, was not statistically significant from Ketac ${ }^{\mathrm{TM}}$ Fil Plus hardness number (see Figure 1).

Figure 1. Vicker hardness number (VHN) of GIC and different formulations of FFMGIC. There was no statistical significance difference in hardness observed after the addition of flax fibres.

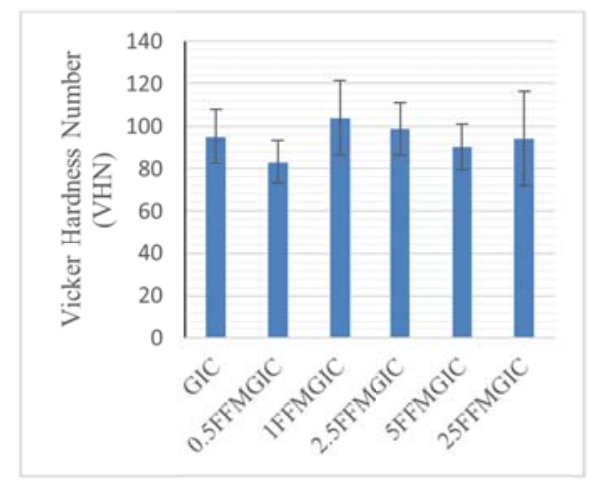

\subsection{Surface topography and mechanical properties}

Figure 2 showed uniform distribution of the stiffness and roughness ( $\mathrm{Ra}$ ) across the surface of GIC samples. For $10 \times$ $10 \mathrm{\mu m}^{2}$ scan size, the recorded Ra value was $58 \mathrm{~nm}$ as given in Table 1. Stiffness was close to Gaussian distribution with mean $2 \mathrm{GPa}$ and width $0.7 \mathrm{GPa}$; the peak value for the stiffness was $4.75 \mathrm{GPa}$. Young's modules, obtained from scan size of $1 \times 1 \mathrm{~m}^{2}$, had clean Gaussian with mean 1.6 GPa and width $0.4 \mathrm{GPa}$. These results suggest a single-phase material. 
Small areas of low and high stiffness were also visible through the samples. These areas could be due to the presence of topographical features (e.g., pinholes and scratches) or unspecific interactions of the silicon tip with these features.

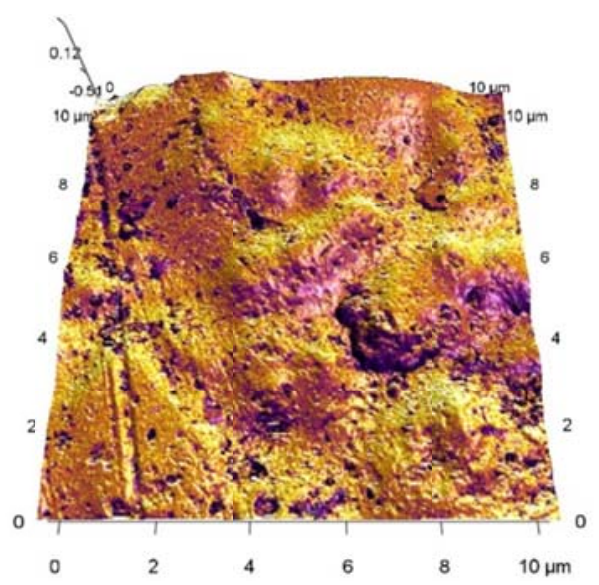

(a)

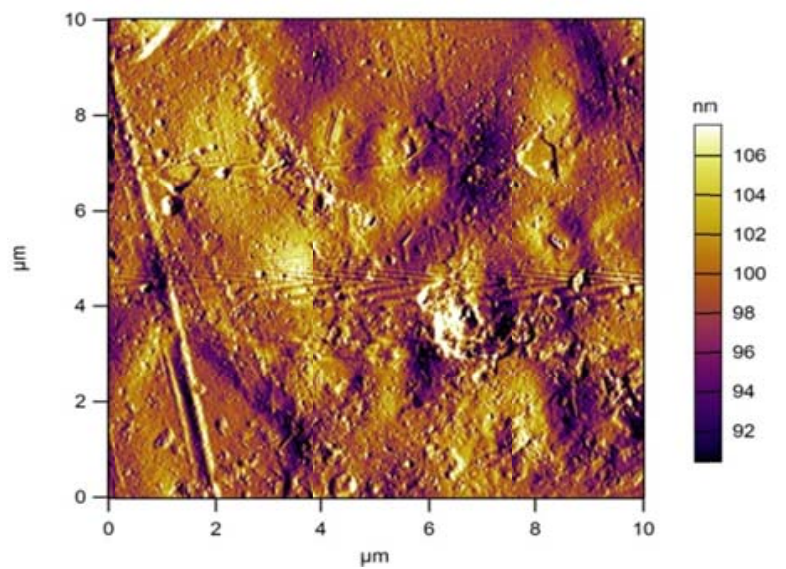

(c)

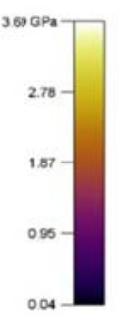

$\underline{\underline{\underline{I}}}$

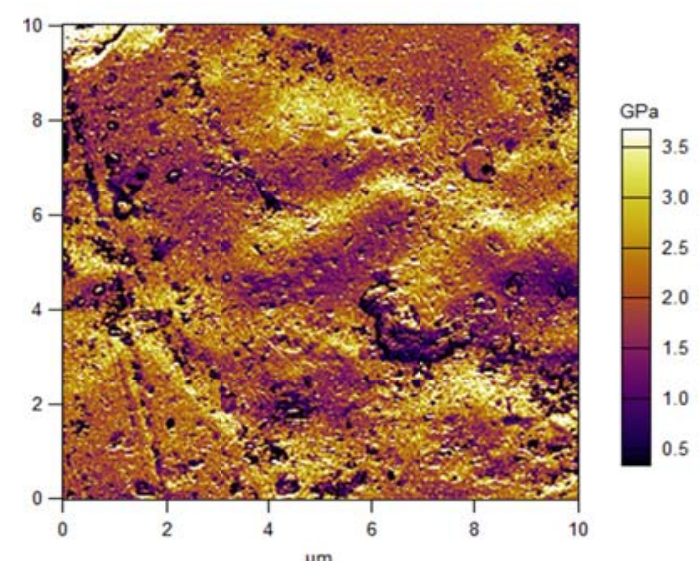

(b)

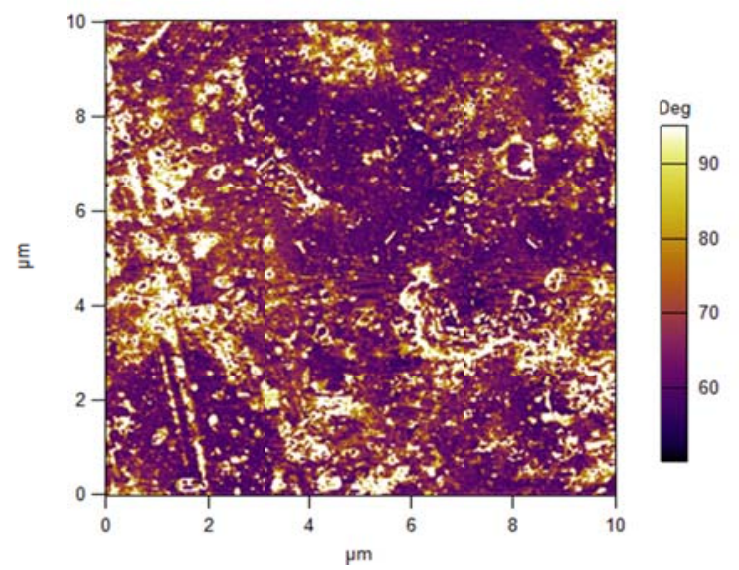

(d)

(e)

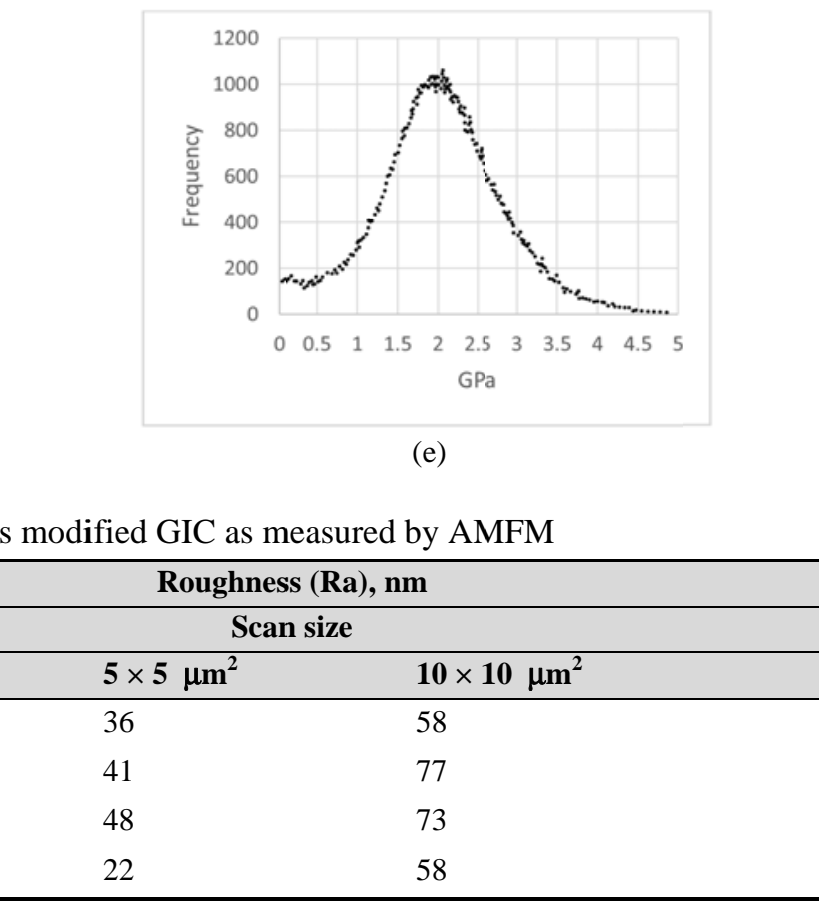

Figure 2. GIC: a) topography with overlayed stiffness map- single phase structure, b) stiffness map, c) topography (high image) showing some surface roughness, d) phase contrast image demonstrating uniform distribution of different phases in the material, and (e) histogram showing the distribution of stiffness across the sample.

Table 1. Surface roughness (Ra) values of GIC and flax-fibres modified GIC as measured by AMFM

\begin{tabular}{|c|c|c|c|c|}
\hline \multirow{3}{*}{ Material Code } & \multirow{3}{*}{ wt $\%$ of fibers } & \multicolumn{3}{|c|}{ Roughness (Ra), nm } \\
\hline & & \multicolumn{3}{|c|}{ Scan size } \\
\hline & & $1 \times 1 \mu \mathrm{m}^{2}$ & $5 \times 5 \mu \mathrm{m}^{2}$ & $10 \times 10 \mu \mathrm{m}^{2}$ \\
\hline GIC & 0 & 8 & 36 & 58 \\
\hline 1 FFMGIC & 1 & 8 & 41 & 77 \\
\hline 5 FFMGIC & 5 & 11 & 48 & 73 \\
\hline 25 FFMGIC & 25 & 6 & 22 & 58 \\
\hline
\end{tabular}



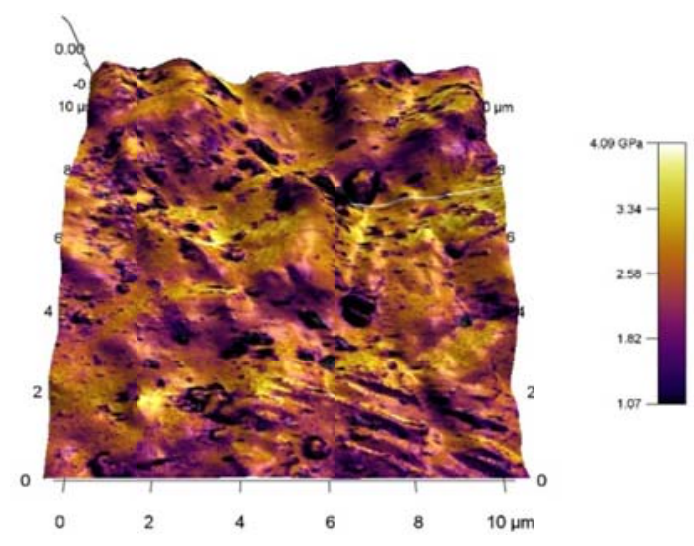

(a)

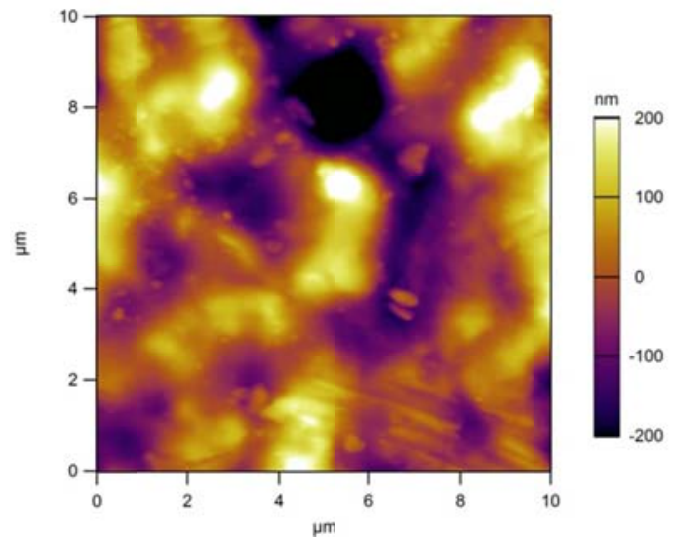

(c)

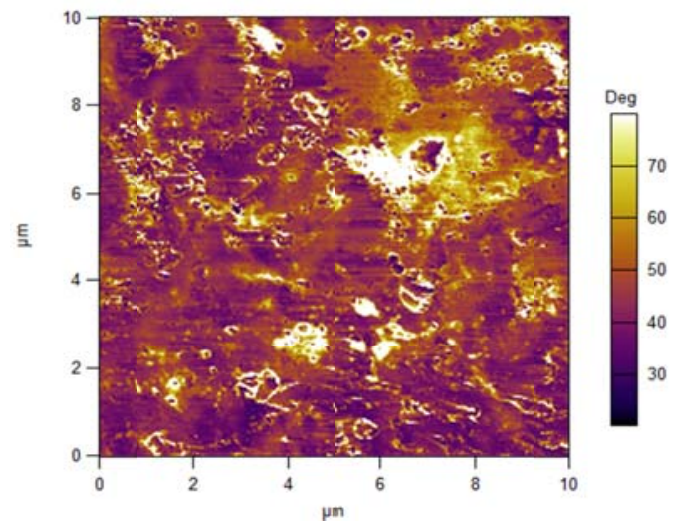

(e)

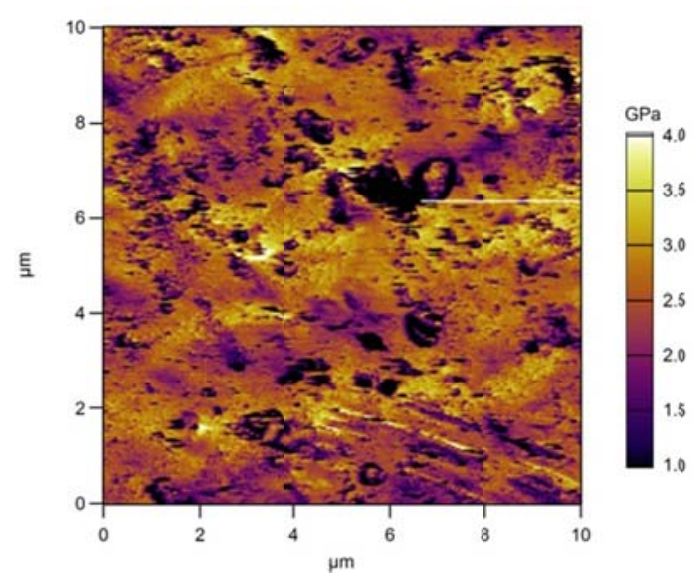

(b)

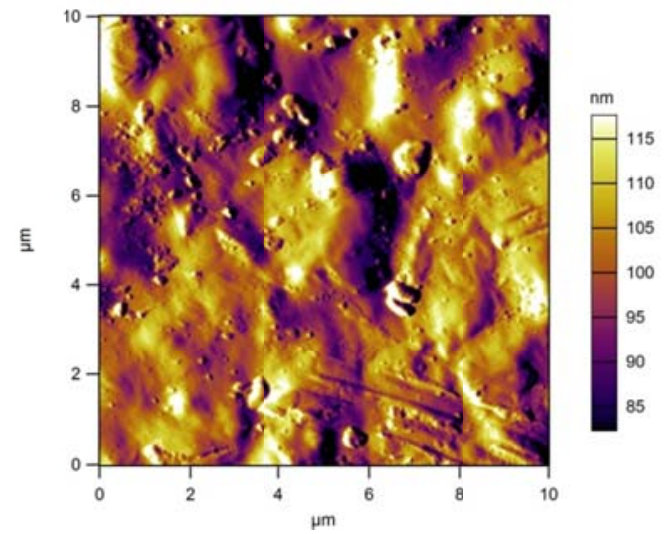

(d)

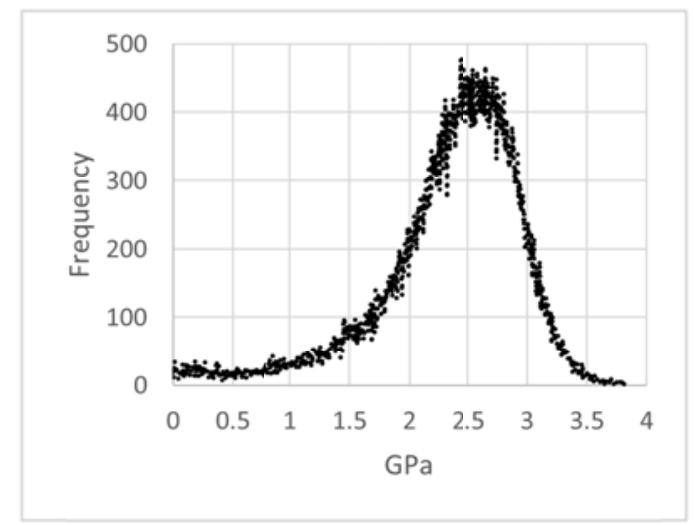

(f)

Figure 3. 1 FFMGIC: a) topography with overlayed stiffness map-visible regions of low stiffens suggesting the bi - phasic nature of the material, b) stiffness map, c) amplitude and topography (high image) showing some surface roughness as well as the presence of visible particles, d) phase contrast image showing zones of different stiffness randomly distributed across the sample, and (e) histogram showing the distribution of stiffness across the sample.

Incorporation of $1 \mathrm{wt} \%$ short flax fibres resulted in insignificant increase of peak stiffness values. Several regions with low stiffness (see Figure 3) were also present on the samples. The stiffness distribution (i.e., histogram) skewed towards lower stiffness values indicating the bi-phasic nature of the samples or the presence of topographical features (e.g., holes). This skewed distribution was not observed for small scan size $\left(1 \times 1 \mu^{2}\right)$; for this scan size, a more uniform surface was observed. The data had Gaussian distribution with $0.17 \mathrm{GPa}$ width and $2.34 \mathrm{GPa}$ mean. The maximum stiffness reached 
3.9 GPa. These results corresponded well with the increase of roughness, particularly in large scan sizes ( $\mathrm{Ra}=77 \mathrm{~nm})$ and the appearance of asperities on the surface of the samples.

With further increase in the filler content ( $5 \mathrm{wt} \%$ ), the distribution profile skewed towards higher values of stiffness. The skewed distribution was observed for all scanned sizes indicating an actual increase in surface stiffness. Gaussian fitting with the central part of the data had mean of 2.19 GPa and very high width of 1.2 GPa. Interestingly areas of low stiffness were more uniformly distributed across the surface (see Figure 4); these areas however did not correspond to any topographical feature suggesting the presence of actual soft zones on the surface. Generally, the maximum stiffness (3.56 GPa) was not affected by the filler content.

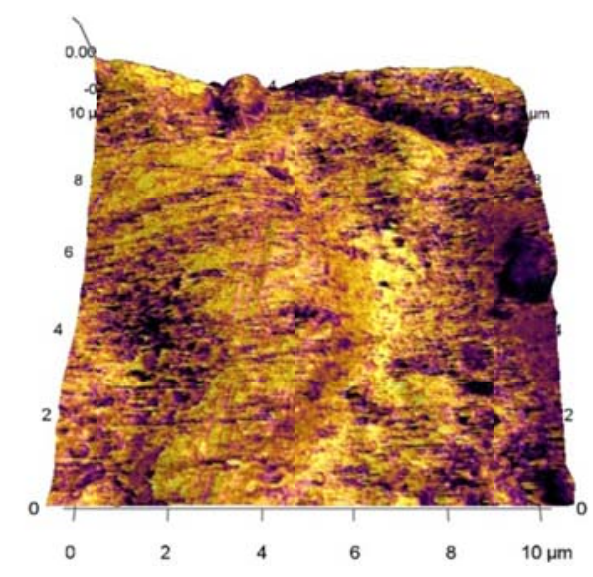

(a)

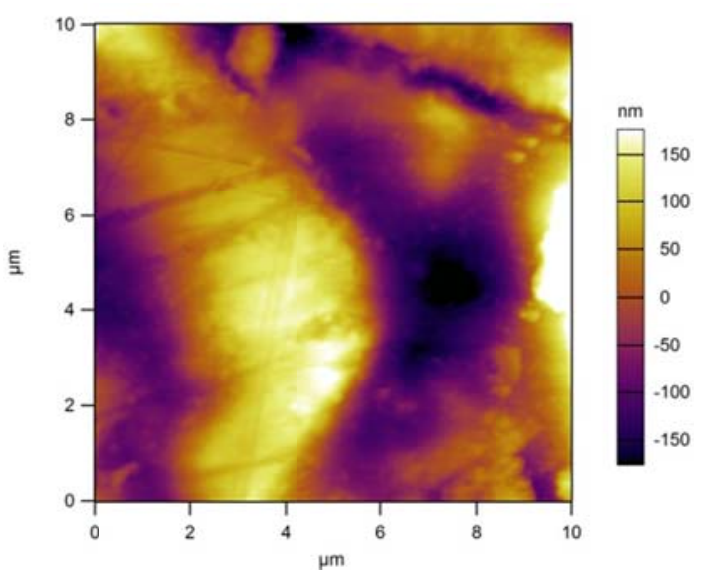

(c)

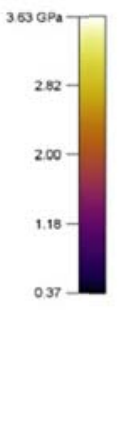

$$
\text { (1) }
$$

Figure 4. 5 FFMGIC: a) topography with overlayed stiffness mapuniformly distributed visible regions of low stiffens indicating the bi-phasic nature of the material, b) stiffness map, c) topography (high image) showing some surface roughness as well as the presence of visible particles, d) phase contrast image showing regions of high stiffness suggesting the bi-phasic material, and (e) histogram showing the distribution of stiffness across the sample; histogram skewed towards higher stiffness further indicating the biphasic nature of the material.

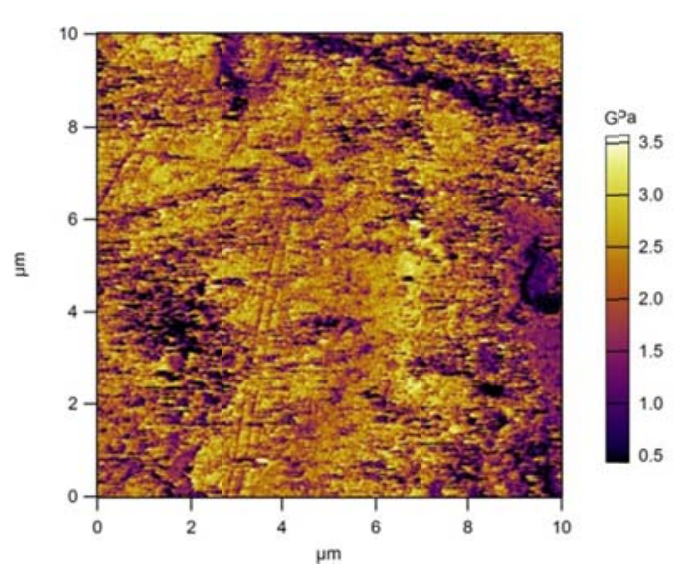

(b)

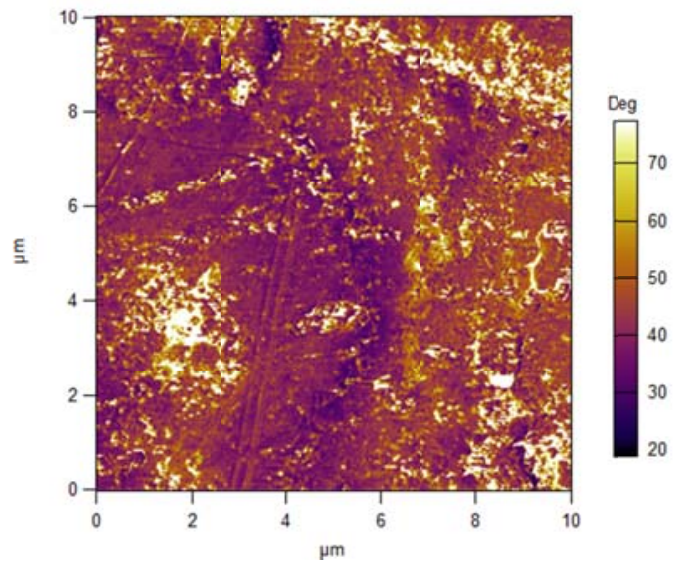

(d)

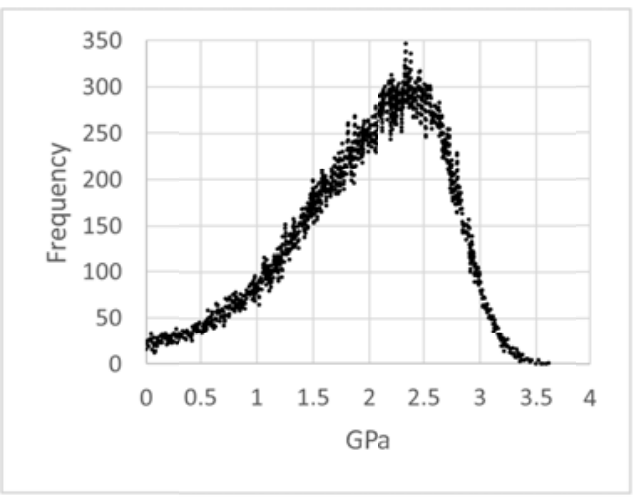

(e) 
The increase of the filler content to $25 \mathrm{wt} \%$ resulted in drop of the maximum stiffness to $2.85 \mathrm{GPa}$. At $10 \times 10 \mu \mathrm{m}^{2}$ scan size, the distribution of the stiffness was very uniform (Gaussian distribution) with mean 1.9 GPa and width 0.27 GPaFigure 5. The stiffness distribution was even more uniform at low scan sizes, the increase in the stiffness (bright regions) was only observed around asperities.
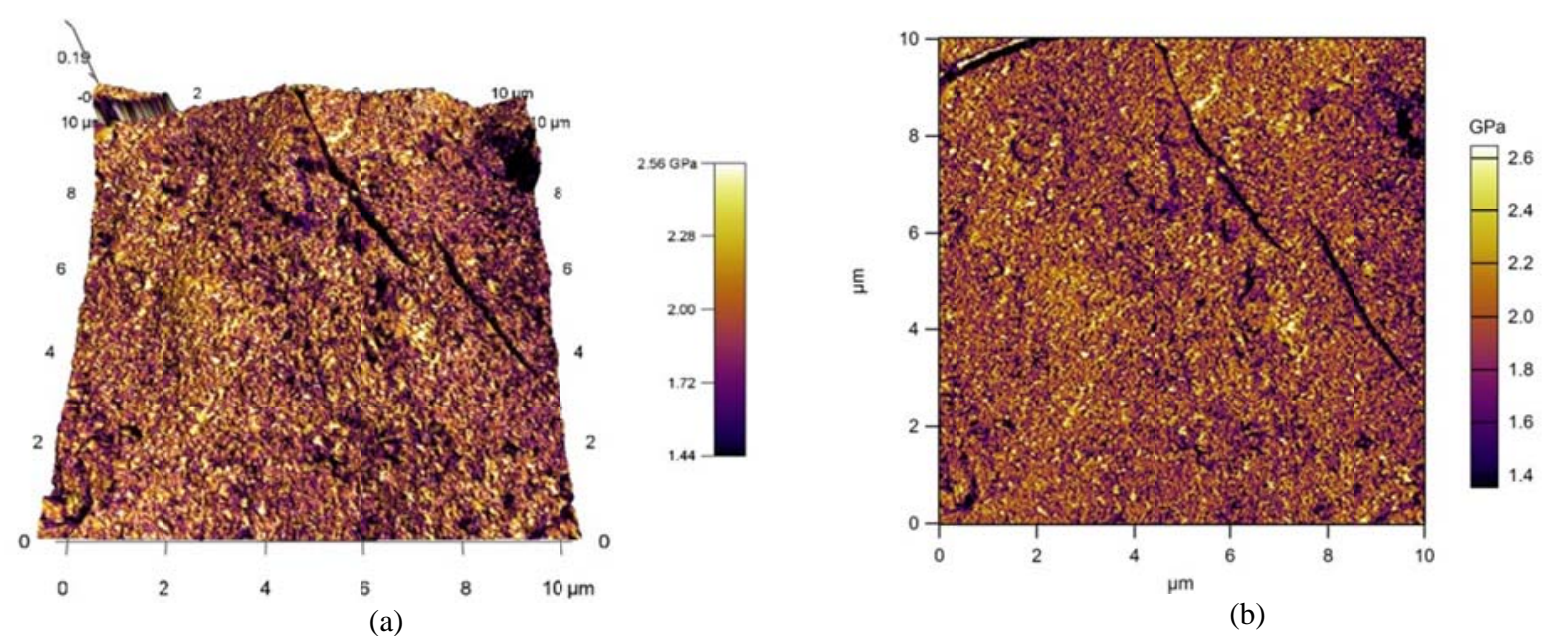

(a)

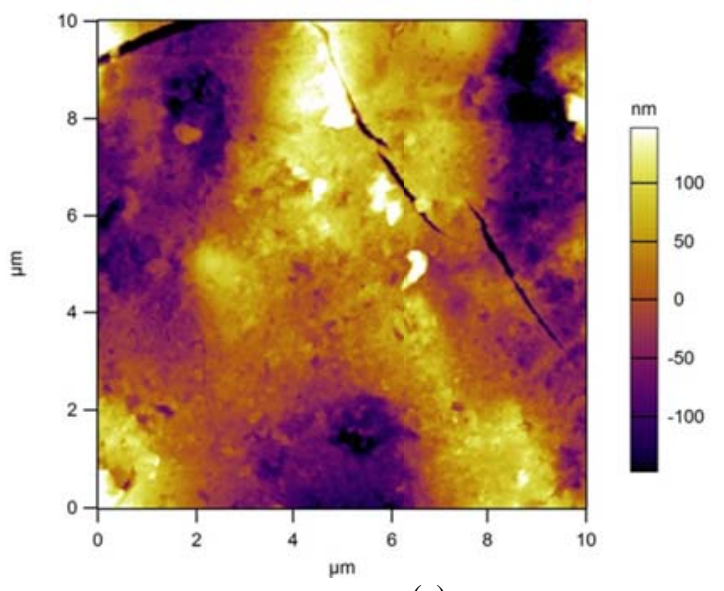

(c)

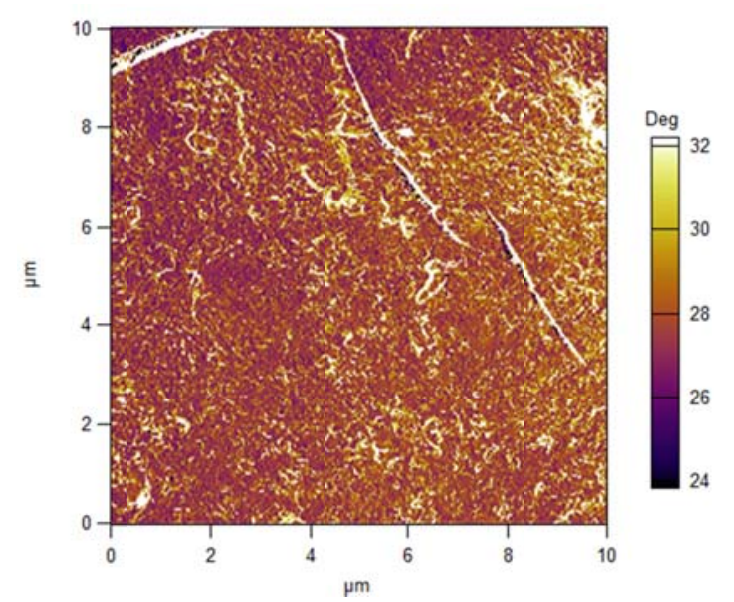

(d)

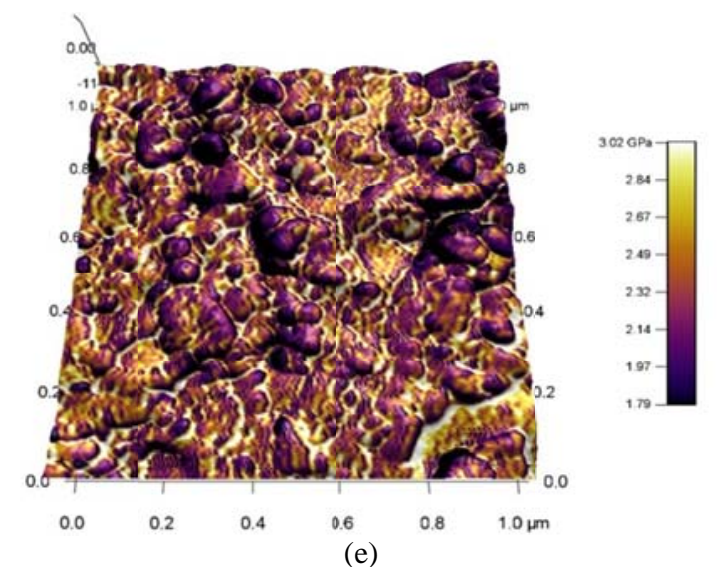

(e)

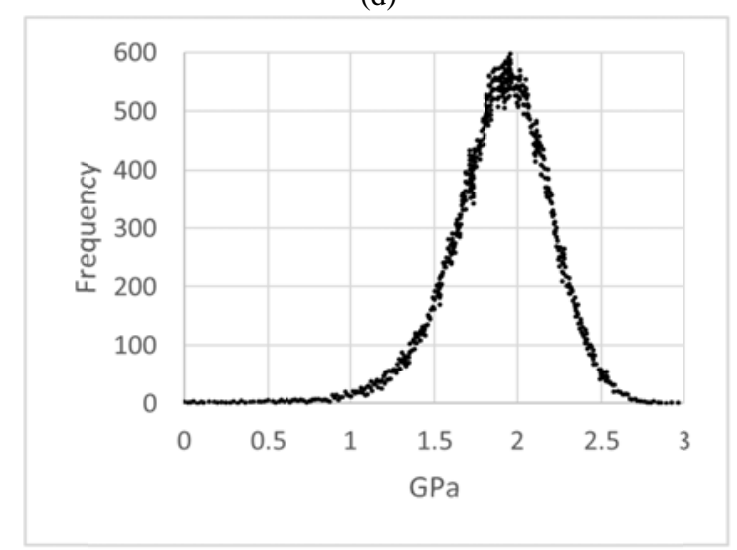

(f)

Figure 5. 25 FFMGIC: a) topography with overlayed stiffness map-visible regions of low stiffens, uniformly distributed across the sample, suggesting the bi-phasic nature of the material, b) stiffness map, c) topography (high image) showing some surface roughness as well as the presence of visible particles, d) phase contrast showing uniform structure with some cracks/scratches across the surface, e) topography of the samples with overlayed stiffness map $1 \times 1 \mu^{2}$-visible regions of low stiffens suggesting the bi-phasic nature of the material, and (f) histogram showing the distribution of stiffness across the sample $\left(10 \times 10 \mu \mathrm{m}^{2}\right)$. 
Generally, the Ra value varies with the filler content and scan size-Table 1. The number/density/sizes of asperities on the sample surface decreased with increasing the filler content.

\section{Discussion}

Currently, researches aim at developing materials with suitable characteristics (e.g., smoothness, hardness and mechanical properties) to meet both dentist and patient's expectations. In this study, flax fibres were incorporated into glass ionomer restorative materials in order to develop materials with higher stiffness while maintaining surface texture and hardness of GIC. This study therefore aimed to investigate the effect of flax fibres, as natural materials, on surface hardness, roughness and micromechanical stiffness of GIC filling materials.

\subsection{Microhardness}

Surface hardness is an important property used to measure the setting reaction ${ }^{[27]}$ and the interaction of materials with the surrounding environment ${ }^{[28]}$. Hardness is highly correlated with compressive, flexure and wear properties ${ }^{[29]}$. In the present study, incorporation of flax fibres produced no significant change in the hardness number of GIC; this may indicate that the flax fibres did not interfere with the setting reaction of GIC. The microhardness value obtained for $\mathrm{Ketac}^{\mathrm{TM}}$ Fil Plus is higher than that recorded in literature ${ }^{[30]}$; this could be due to the variation of testing conditions (e.g., load and time of its application), powder/liquid ratio, and preparation method. According to the results of the hardness test, there was no enough evidence to reject the null hypothesis.

\subsection{Surface topography and mechanical properties}

Surface roughness determines the clinical quality and performance of the restorative materials. For aesthetic restorative materials, surface smoothness is highly important for better aesthetic. Rough surface, however, encourages plaque accumulation and hence gingival inflammation and discoloration of aesthetic restorations would be expected. Surface roughness was measured as "the mean value of the heights and depths of the roughness profile" and recorded as "Ra" value ${ }^{[31]}$. In the present study, all sample surfaces were prepared against celluloid strips that formed the smoothest possible surface for restorative materials in clinical applications. Accordingly, there was no polishing carried out after sample preparation in order to simulate the clinical situation ${ }^{[32]}$. The increase in surface roughness, particularly in large scan size, with 1 FFMGIC could be associated with the appearance of asperities on the surface. These asperities could be due to the presence of fibres near or at the surface. Further increase in surface roughness with 5 FFMGIC, however, could not be mainly attributed to the presence of asperities as in 1 FFMGIC due to the lower number/density of asperities on the surface of 5 FFMGIC samples than those seen with GIC and 1 FFMGIC samples. Furthermore, the size of the asperities seen with 5 FFMGIC was smaller than those on GIC and 1 FFMGIC samples. The increase in surface roughness of 5 FFMGIC could be due to the high density of the fibres and the formation of more homogenous bi - phasic material with a uniform distribution of the fibres within the structure ${ }^{[33]}$. The bi - phasic structure of FFMGIC was confirmed by skewed distribution of stiffness and topography. This skewing was towards low (in case of 1 FFMGIC) or high stiffness (in case of 5 FFMGIC). For samples with $25 \mathrm{wt} \%$ fibres, the surface roughness values for all analyzed sizes decreased when compared with other formulations. This could be explained by the large number/density of uniformly distributed smooth fibres in the structure. For GIC, however, the uniform distribution of the stiffness and surface morphology suggested a single phase material. Small areas of low stiffness were also seen for GIC; these areas could be pinholes, scratches, protrusions and unspecific interactions of the silicon tip with these features. Regardless of the bi - phasic nature of flax fibres modified glass ionomer restorative materials, the fibres were uniformly distributed and well integrated within the glass matrix without any visible interfacial separation. This could be indicated by the increase in stiffness with the addition of flax fibres, up to $5 \mathrm{wt} \%$ in particular.

Normally, bacteria adheres and colonizes to rough surfaces. The threshold roughness value "Ra" is $0.2 \mu \mathrm{m}$; any roughness below this limit has no major effect on the supra-and sub-gingival plaque accumulation. Any roughness value above 
$0.2 \mu \mathrm{m}$, however, significantly increased bacterial adhesion and plaque accumulation ${ }^{[34]}$. In this study, the measured roughness values are lower than the threshold value reported in literatures.

Interestingly, the increase in stiffness was observed with the addition of up to $5 \mathrm{wt} \%$ of flax fibres; a drop in stiffness, however, was observed for $25 \mathrm{wt} \%$. Furthermore, it was observed that the stiffness distribution was directly related to fibres' content. A gradual increase of the areas with low stiffness, which were associated with the flax fibres, was observed. Importantly, for all samples, the stiffness distribution, thus filler, was uniform. The most uniform distribution of the stiffness was observed for the samples with $25 \mathrm{wt} \%$ flax. AMFM investigations on small scan sizes confirmed that the stiffness distribution was very uniform. The increase in the stiffness (bright regions) was observed only around asperities; this phenomenon could be explained by either a decrease in the contact area between the tip and the surface, or 'tight' junction at the interfaces between material components reducing stress accumulation. The latter situation is more likely and corresponds well with the structural analysis of the material ${ }^{[35]}$. According to the results of surface roughness and mechanical properties, there was an enough evidence to reject the null hypothesis.

The effect of flax fibres on setting characteristic (kinetic and time), mechanical (compression and flexural) properties, radiopacity as well as biocompatibility of GIC restorative materials will be considered in the future work. Another direction for the future work will be the surface modification of flax fibres for further improvement of materials' stiffness.

\section{Conclusion}

1) Addition of flax fibres produced no significant changes in surface microhardness of GIC.

2) Qualitative imaging using AMFM showed the presence of a single phase for GIC, while biphasic structure was observed for FFMGICs. Regardless of the bi-phasic nature observed for flax fibres modified formulations, the flax fibres were uniformly distributed and well integrated within the glass ionomer matrix without any visible interfacial separation.

3) Addition of flax fibres up to $5 \mathrm{wt} \%$ produced a significant increase in surface roughness. This was related to the increased content of fibres protruding on the surface as well as the heterogeneous, biphasic characteristics of flax fibres modified glass ionomer materials.

4) Importantly, the incorporation of flax fibres up to $5 \mathrm{wt} \%$ significantly increased stiffness. The increase of the filler content to $25 \mathrm{wt} \%$, however, resulted in drop of the maximum stiffness.

5) The number/density/sizes of asperities on the sample surface decreased with increasing the filler content.

\section{Acknowledgment}

This project was funded by the Deanship of Scientific Research (DSR), King Abdulaziz University, Jeddah, under grant no (440/254 /1434). The authors, therefore acknowledge with thanks DSR technical and financial support.

\section{Conflict of interest}

The authors declare that there is no conflict of interest.

\section{References}

[1] Bertolini MJ, Palma-Dibb RG, Zaghete MA, et al. Evaluation of glass ionomer cements properties obtained from niobium silicate glasses prepared by chemical process. J Non-Cryst Solids. 2005; 351: 466-71. http://dx.doi.org/10.1016/j.jnoncrysol.2005.01.040 
[2] Bertolini MJ, Zaghete MA, Gimenes R, et al. Determination of the properties of an experimental glass polyalkenoate cement prepared from niobium silicate powder containing fluoride. Dent Mater. 2008; 24: 124-8. http://dx.doi.org/10.1016/j.dental.2007.03.005

[3] Bertolini MJ, Zaghete MA, Gimenes R, et al. Preparation of new glass systems by the polymeric precursor method for dental applications. J Non-Cryst Solids. 2004; 344: 170-5. http://dx.doi.org/10.1016/j.jnoncrysol.2004.08.063

[4] Boaventura JMC, Padovani MJ, Padovani GC, et al. Tissue response to experimental dental cements prepared from a modified power glass composition. Dent Mater J. 2012; 31(4): 583-92. http://dx.doi.org/10.4012/dmj.2011-235

[5] Kromer KH. Physical properties of flax fibre for non-textile-use. RES. AGR. ENG. 2009; 55(2): 52-61.

[6] Stamboulis A, Baillie CA, Garkhail SK, et al. Environmental durability of flax fibres and their composites based on polypropylene matrix. Applied Composite Materials. 2000; 7: 273-94. http://dx.doi.org/10.1023/A:1026581922221

[7] Czemplik M, Kulma A, Bazela K, et al. The biomedical potential of genetically modified flax seeds overexpressing the glucosyltransferase gene. BMC Complement Altern Med. 2012; 12(1): 251. http://dx.doi.org/10.1186/1472-6882-12-251

[8] $\mathrm{Hu}$ C, Yuan YV, Kitts DD. Antioxidant activities of the flaxseed lignan secoisolariciresinol diglucoside, its aglycone secoisolariciresinol and the mammalian lignans enterodiol and enterolactone in vitro. Food Chem Toxicol. 2007; 45(11): $2219-27$. http://dx.doi.org/10.1016/j.fct.2007.05.017

[9] Shehata MM, Mona HAD, El Hariri DM. Compressive strength, solubility and micro-leakage of flax fibers reinforced zinc oxide eugenol dental cement material. Flax and other bast plants Symp. 1997 Sep30 and Oct 1; INF.

[10] Ionescu A, Wutscher E, Brambilla E, et al. Influence of surface properties of resin-based composites on in vitro Streptococcus mutans biofilm development. Eur J Oral Sci. 2012; 120(5): 458-65. http://dx.doi.org/10.1111/j.1600-0722.2012.00983.x

[11] Mei L, Busscher HJ, Van der Mei HC, et al. Influence of surface roughness on streptococcal adhesion forces to composite resins. Dent Mater. 2011; 27(8): 770-8. http://dx.doi.org/10.1016/j.dental.2011.03.017

[12] Einwag J, Ulrich A, Gehring F. In: vitro plaque accumulation on different filling materials. Oralprophylaxe. 1990; 12(1): 22-5. PMid:2206604.

[13] Quirynen M, Bollen CML. The influence of surface roughness and surface-free energy on supra- and subgingival plaque formation in man. A review of the literature. J Clin Periodontol. 1995; 22(1): 1-14. http://dx.doi.org/10.1111/j.1600-051X.1995.tb01765.x

[14] Quirynen M, Bollen CM, Papaioannou W, et al. The influence of titanium abutment surface roughness on plaque accumulation and gingivitis: short-term observations. Int J Oral Maxillofac Implants. 1996; 11(2): 169-78. PMid:8666447.

[15] Quirynen M, Marechal M, Busscher HJ, et al. The influence of surface free energy and surface roughness on early plaque formation. An in vivo study in man. J Clin Periodontol. 1990; 17(3): 138-44.

http://dx.doi.org/10.1111/j.1600-051X.1990.tb01077.x

[16] Gedik R, Hürmüzlü F, Coskun A, et al. Surface roughness of new microhybrid resin-based composites. J Am Dent Assoc. 2005; 136(8): 1106-12. http://dx.doi.org/10.14219/jada.archive.2005.0314

[17] Lin S, Caputo AA, Eversole LR, et al. Topographical characteristics and shear bond strength of tooth surfaces cut with a laser-powered hydrokinetic system. J Prosthet Dent. 1999; 82(4): 451-5. http://dx.doi.org/10.1016/S0022-3913(99)70033-8

[18] Marghalani HY. Effect of finishing/polishing systems on the surface roughness of novel posterior composites. J Esthet Restor Dent. 2010; 22(2): 127-38. http://dx.doi.org/10.1111/j.1708-8240.2010.00324.x

[19] Lee I, Chang J, Ferracane J. Slumping resistance and viscoelasticity prior to setting of dental composites. Dent Mater. 2008; 24(12): 1586-93. http://dx.doi.org/10.1016/j.dental.2008.03.014

[20] Xia L, Chen P, Wang Y, et al. Three-dimensional measuring technique for surface topography using a light-sectioning microscope. Appl Opt. 2012; 51(8): 1162-70. http://dx.doi.org/10.1364/AO.51.001162

[21] Kakaboura A, Fragouli M, Rahiotis C, et al. Evaluation of surface characteristics of dental composites using profilometry, scanning electron, atomic force microscopy and gloss-meter. J Mater Sci Mater Med. 2007; 18(1): 155-63. http://dx.doi.org/10.1007/s10856-006-0675-8

[22] Dos Santos PH, Pavan S, Suzuki TYU, et al. Effect of fluid resins on the surface roughness and topography of resin composite restorations analyzed by atomic force microscope. J Mech Behav Biomed Mater. 2011; 4(3): 433-9. http://dx.doi.org/10.1016/j.jmbbm.2010.12.004

[23] Giacomelli L, Derchi G, Frustaci A, et al. Surface roughness of commercial composites after different polishing protocols: an analysis with atomic force microscopy. Open Dent J. 2010 Sep 15; 4: 191-4. http://dx.doi.org/10.2174/1874210601004010191

[24] Varanda E, Do Prado M, Simão RA, et al. Effect of in-office bleaching agents on the surface roughness and morphology of different dental composites: an AFM study. Microsc Res Tech. 2013; 76(5): 481-5. http://dx.doi.org/10.1002/jemt.22190

[25] Picas L, Rico F, Scheuring S. Direct measurement of the mechanical properties of lipid phases in supported bilayers. Biophys J. 2012; 102(1): L01-3. http://dx.doi.org/10.1016/j.bpj.2011.11.4001 
[26] Louvet E, Yoshida A, Kumeta M, et al. Probing the stiffness of isolated nucleoli by atomic force microscopy. Histochem Cell Biol. 2014; 141(4): 365-81. http://dx.doi.org/10.1007/s00418-013-1167-9

[27] Baloch FA, Mirza AJ, Baloch D. An in-vitro study to compare the microhardness of glass ionomer cement set conventionally versus set under ultrasonic waves. Int J Health Sci (Qassim). 2010; (4): 2.

[28] Bajwa NK. Change in surface roughness of esthetic restorative materials after exposure to different immersion regimes in a cola drink. ISRN Dent. 2014; (353926): 1-6. http://dx.doi.org/10.1155/2014/353926

[29] Bonifácio CC, Kleverlaan CJ, Raggio DP, et al. Physical-mechanical properties of glass-ionomer cements indicated for atraumatic restorative treatment. Australian Dental Journal. 2009; 54: 233-7. http://dx.doi.org/10.1111/j.1834-7819.2009.01125.x

[30] Silva KG, Pedrini D, Dellbem ACB, et al. Microhardness and Fluoride Release of Restorative Materials in Different Storage Media. Braz Dent J. 2007; 18(4): 309-13. http://dx.doi.org/10.1590/S0103-64402007000400007

[31] Markovic L, Jordan RA, Glasser MC, et al. Effects of bleaching agents on surface roughness of filling materials. Dental Materials Journal. 2014; 33(1): 59-63. http://dx.doi.org/10.4012/dmj.2012-217

[32] Ozgünaltay G, Yazici A R, Görücü J. Effect of finishing and polishing procedures on the surface roughness of new tooth-colored restoratives (Review Article). J Oral Rehabil. 2003; 30: 218-24. http://dx.doi.org/10.1046/j.1365-2842.2003.01022.x

[33] Lai YL, Lin YC, Chang CS, et al. Effects of sonic and ultrasonic scaling on the surface roughness of tooth-colored restorative materials for cervical lesions. Oper Dent. 2007; 32: 273-8. http://dx.doi.org/10.2341/06-77

[34] Bollen CM, Papaioanno W, Van Eldere J, et al. The influence of abutment surface roughness on plaque accumulation and peri-implant mucositis. Clin Oral Implants Res. 1996; 7: 201-11. http://dx.doi.org/10.1034/j.1600-0501.1996.070302.x

[35] Kiracofe D, Raman A, Yablon D. Multiple regimes of operation in bimodal AFM: understanding the energy of cantilever eigenmodes. Beilstein J Nanotechnol. 2013; 4: 385-93. http://dx.doi.org/10.3762/bjnano.4.45 